\title{
LETTERS
}

\section{A call to recognize the value in disability}

It was a pleasure to read Dr. Andrew Hogan's article on the social and medical models of disability. ${ }^{1}$ As someone who works at the intersections of public health, disability studies, gender studies and psychology, I was delighted to see Dr. Hogan's eloquent summary of the history of the medical and social models of disability include the perspectives of some feminist disability scholars. What Liz Crow and other feminist disability scholars ${ }^{2-4}$ argue for is an embodied, relational understanding of disability, wherein disability is understood as simultaneously material or physical (i.e., in or of our bodies) and shaped by social interactions, discourses and the environment around us (i.e., experienced through our bodies).

I found this to be the case in my own research on the pregnancy and motherhood experiences of women with physical disabilities. ${ }^{5,6}$ For women with physical disabilities, disability, while experienced as limiting and even frustrating in many ways, was also experienced as a sort of blessing in the perinatal period.

I thought pregnancy was the hard part and it really wasn't. It was easier than [I expected]. All the able-bodied women that I knew were complaining. ... I had it [morning sickness] but I wasn't awful ... I think in part because I've been dealing with physical limitations for so long, I was like, "This is it?" I think a lot of able-bodied women are like, "Ugh, I don't have control over my body now and all the sudden I have to pee 5 times in the night." I know what that's like already, so it wasn't really shocking to me to have the limitations, in terms of what I could do. You have to go with it and make adjustments. I think if you are able-bodied, you might have a harder time with that because you are just used to being able to do whatever you want to do, whenever you want to do it. - Woman with a cervical spinal cord injury. ${ }^{5}$

When understanding disability from a medical model perspective, people with disabilities are considered to be inherently defective and "unruly," and marginalized as a result; they are undesirable unless they are treated or cured. My research, however, shows that there is value in the "unruly" disabled body and that there is much to learn from the experiences of often-marginalized bodies.

As the above quotation suggests, women with physical disabilities may be better able to adapt to or even embrace the bodily changes associated with pregnancy given their experiential knowledge of living with a disabled body, a body that is not always controllable. The pregnancy experiences of women with physical disabilities may challenge the notion that a lack of bodily control during pregnancy (and in general when experienced by people without disabilities) is only negative or detrimental.

From my interviews with women with physical disabilities, I found that, during pregnancy, the embodied experience of disability can be appreciated and offers a reimagination of the "unruly" body. The embodied experience of disability may serve as resource or an opportunity for others to draw on should they experience a substantial bodily change, whether it be pregnancy, injury, illness or aging. As feminist disability scholar Alison Kafer has argued, "rethinking our cultural assumptions about disability ... will benefit all of us."2

With growing populations of older people and people with comorbid conditions, discussions among health care providers and between health care providers and their patients (both disabled and nondisabled) about the various understandings of disability and the value that disability might bring is vital now more than ever.

\section{Lesley A. Tarasoff PhD}

Postdoctoral research fellow, University of Toronto Scarborough, Scarborough, Ont.

- Cite as: CMAJ 2019 April 23;191:E453. doi: $10.1503 / \mathrm{cmaj} .71763$

\section{References}

1. Hogan AJ. Social and medical models of disability and mental health: evolution and renewal. CMAJ 2019;191:E16-8.

2. Kafer A. Feminist, queer, crip. Bloomington (IN): Indiana University Press; 2013.

3. Thomas C. Female forms: experiencing and understanding disability. Buckingham (UK): Open University Press; 1999.

4. Wendell S. The rejected body: feminist philosophical reflections on disability. 1st ed. New York: Routledge; 1996.

5. Tarasoff LA. A qualitative study of embodiment among women with physical disabilities during the perinatal period and early motherhood [unpublished doctoral dissertation]. Toronto: University of Toronto; 2018.

6. Tarasoff LA. "We don't know. We've never had anybody like you before": barriers to perinatal care for women with physical disabilities. Disabil Health J 2017;10:426-33.

Competing interests: None declared. 